\title{
Standard and cardiac-gated phase-contrast magnetic resonance imaging in the clinical course of patients with Chiari malformation Type I
}

\author{
Uwe Max Mauer, M.D. ${ }^{1}$ Andreas Gottschalk, M.D., ${ }^{2}$ Carolin Mueller, M.D., ${ }^{1}$ \\ Linda Weselek, M.D., ${ }^{1}$ Ulrich Kunz, Prof., M.D., ${ }^{1}$ And Chris Schulz, M.D. ${ }^{1}$ \\ Departments of ${ }^{1}$ Neurosurgery and ${ }^{2}$ Radiology, German Armed Forces Hospital of Ulm, Germany
}

\begin{abstract}
Object. The causal treatment of Chiari malformation Type I (CM-I) consists of removing the obstruction of CSF flow at the level of the foramen magnum. Cerebrospinal fluid flow can be visualized using dynamic phase-contrast MR imaging. Because there is only a paucity of studies evaluating CSF dynamics in the region of the spinal canal on the basis of preoperative and postoperative measurements, the authors investigated the clinical usefulness of cardiacgated phase-contrast MR imaging in patients with CM-I.

Methods. Ninety patients with CM-I underwent preoperative MR imaging of CSF pulsation. Syringomyelia was present in 59 patients and absent in 31 patients. Phase-contrast MR imaging of the entire CNS was used to investigate 22 patients with CM-I before surgery and after a mean postoperative period of 12 months (median 12 months, range 3-33 months). In addition to the dynamic studies, absolute flow velocities, the extension of the syrinx, and tonsillar descent were also measured.

Results. The changes in pulsation were highly significant in the region of the (enlarged) cistern $(\mathrm{p}=0.0005)$. Maximum and minimum velocities (the pulsation amplitude) increased considerably in the region where the syrinx was largest in diameter. The changes of pulsation in these patients were significant in the subarachnoid space in all spinal segments but not in the syrinx itself and in the central canal.

Conclusions. The demonstration of CSF flow pulsation can contribute to assessments of surgical outcomes. The results presented here, however, raise doubts about current theories on the pathogenesis of syringomyelia. (DOI: 10.3171/2011.7.FOCUS11105)
\end{abstract}

\section{Key Words • Chiari malformation Type I • syringomyelia • phase-contrast magnetic resonance imaging • cerebrospinal fluid pulsation}

$\mathrm{F}$ OR decades it was assumed in the literature that patients with CM-I were a homogenous group. Milhorat, ${ }^{21}$ however, defined 5 subtypes of CM-I associated with different causative factors: 1) constriction of the posterior cranial fossa occurring with classic CM-I; 2) downward traction of the spinal cord occurring with tethered cord syndrome and occult tethered cord syndrome; 3 ) hypermobility of the atlantooccipital and atlantoaxial joints; 4) increased intracranial pressure; and 5) intraspinal hypotension. Yet there is general agreement that the most common cause of CM-I is a smaller than normal posterior fossa volume. ${ }^{1}$

Abbreviation used in this paper: $\mathrm{CM}-\mathrm{I}=$ Chiari malformation Type I.
Because impaired CSF pulsations are an essential precondition for the development of syringomyelia, their visualization and quantification play a crucial role in the understanding of individual cases and the planning of causal treatment. In the past, a number of different MR imaging techniques have been developed and described that allow CSF movement to be assessed in terms of velocity and direction. $2,8,15,17,29,31,32$ At present, the most commonly used technique is cardiac-gated phase-contrast MR imaging. In the 1990s, this method was introduced and established primarily for investigations of the brain by Quencer et al.,27 Levy et al., ${ }^{17,18}$ and Nitz and colleagues ${ }^{23}$-as well as by Schroth and Klose $^{32}$ in Germany-and has been verified in several studies. ${ }^{3,5,18}$ This method allows MR images of CSF flow to be displayed in a cine mode throughout the cardiac cycle. 


\section{U. M. Mauer et al.}

Although the international literature reports that dynamic phase-contrast MR imaging is the standard method for diagnosing patients with CM-I, ${ }^{16}$ it is a technique that is not routinely used in clinical practice. The visualization of CSF flow in the region of the cerebrum has been studied extensively and analyzed in a structured manner. ${ }^{13-15}$ There is, however, a paucity of structured studies evaluating CSF dynamics in the region of the spinal canal in a reasonable number of patients. For this reason, we investigated the clinical usefulness of cardiac-gated phasecontrast MR imaging for the visualization of CSF flow in the spinal canal of patients with CM-I and assessed absolute CSF flow velocities, in particular postoperative changes.

\section{Methods}

\section{Study Population}

The study included all patients with CM-I who underwent MR imaging at the Departments of Neurosurgery and Radiology, German Armed Forces Hospital of Ulm, from January 1, 2003, to September 31, 2007. Apart from standard projections, we extensively studied CSF motion using phase-contrast MR imaging of the craniocervical junction, the cervical spine, the thoracic spine, and the lumbar spine in the median sagittal plane for the visualization of craniocaudal CSF flow.

\section{Assessments and Outcome Variables}

We determined the position of the cerebellar tonsils in relation to the foramen magnum. Because the dorsal border of the foramen magnum was not clearly defined after surgery, the location of the cerebellar tonsils was determined in the following manner. A straight line was drawn at the level of the endplate of $\mathrm{C}-2$, and the length of the perpendicular line from the tip of the cerebellar tonsils to the aforementioned straight line was measured. The extension of the syrinx was expressed by the vertebral levels, along which the syrinx extended in the craniocaudal direction (for example, C4-T2). The size of the syrinx in the axial plane was measured at the site where the syrinx was largest in diameter. Apart from absolute values, we determined relative values on the basis of the overall anterior-posterior diameter of the spinal canal (anterior-posterior diameter ratio).

Phase-contrast MR imaging studies can be analyzed qualitatively and quantitatively. A qualitative analysis consists of evaluating the homogeneity of CSF flow and allows examiners to detect CSF flow obstructions. In addition, the direction of CSF flow can be determined in the various compartments, such as the subarachnoid space or the syrinx cavity. In a quantitative analysis, absolute CSF velocities can be measured on the basis of the direction vector. Cranial flow is displayed in black (negative sign) on the MR image and caudal flow in white (positive sign).

For every measuring site, we also assessed maximum velocities (maximum velocities [+], CSF flow in the cranial direction), minimum velocities (maximum velocities $[-]$, CSF flow in the caudal direction), mean velocities, and median velocities.

\section{Results}

\section{Syringomyelia Groups}

In the aforementioned period, 90 patients with CM-I (61 women, 29 men, mean age 39 years, median age 40 years, range 3-80 years) were examined and treated at our institution in accordance with the protocol described above. Fifty-nine of these patients had syringomyelia (41 women, 18 men, mean age 44 years, median age 47 years, range 6-80 years) and 31 did not have syringomyelia (20 women, 11 men, mean age 28 years, median age 29 years, range 3-65 years). Two patients were included in both groups because they developed syringomyelia over a period of 4 years. For this reason, their earlier data pertained to the group of patients without syringomyelia and their later data to the group of patients with syringomyelia. Particularly noteworthy is that the mean age of patients without syringomyelia was significantly lower $(p<0.0005)$ than that of patients with syringomyelia.

Patients without syringomyelia mainly reported general disease symptoms. For example, there was a significant difference in the frequency of headaches between patients with and without syringomyelia $(\mathrm{p}<0.05)$. The difference in neurological deficits and other symptoms involving the extremities was similarly significant. It was interesting to note that a loss of temperature sensation, which is a typical symptom of syringomyelia, was reported by only $6(15 \%)$ of 40 patients with this data available.

No more than 2 patients with syringomyelia and 4 patients without syringomyelia had been treated with ventriculoperitoneal shunting. Conservative treatment was indicated in only 3 patients with syringomyelia and in 20 patients without syringomyelia.

\section{Surgical History and Reoperation}

In the group of patients with syringomyelia, 38 had undergone initial surgery at our institution. Six patients had undergone initial surgery at another institution and underwent revision surgery at our hospital. Three patients had undergone surgery only at another institution. In the group of patients without syringomyelia, 6 patients had undergone initial surgery at our institution. No patient who had undergone initial surgery at another institution required revision surgery. Two patients had undergone surgery only at another institution. We recommended surgery for a total of 10 patients who declined to undergo surgical treatment at that time.

Of the 44 patients who underwent surgery for CM-I, $3(7 \%)$ required reoperation at the craniocervical junction. In the first case, the patient presented with a new cyst in the region of the foramen of Magendie and syringobulbia after 2 years. In the second case, decompression had not been wide enough. In the third case, an enlarged obex membrane had gone unnoticed during initial surgery. In all 3 patients, syringomyelia symptoms and imaging findings improved after revision surgery.

\section{Anatomical Differences}

The cerebellar tonsils were located an average of 13 $\mathrm{mm}$ (median $11 \mathrm{~mm}$, range 5-38 $\mathrm{mm}$ ) below the level of 


\section{Cardiac-gated phase-contrast MR imaging and CM-I}

the foramen magnum in patients with syringomyelia and an average of $16 \mathrm{~mm}$ (median $13 \mathrm{~mm}$, range 5-67 mm) below the foramen magnum in patients without syringomyelia. This difference between the 2 groups of patients was not significant $(\mathrm{p}=0.19)$.

The C-6 level was the spinal segment most commonly affected by syringomyelia ( 35 patients), followed by the C-5 and C-7 levels (34 patients each). In 16 patients, the syrinx extended over more than 15 vertebral levels. The C-6 level was also the region where the syrinx was largest in diameter in the majority of cases (8 patients).

\section{Neuroimaging}

A complete series of MR images that were obtained before surgery and after a mean postoperative period of 1 year (median 12 months, range 3-33 months) were available for 22 patients. In these cases, the craniocaudal extension of the syrinx had decreased by an average of 2.5 vertebral levels (median 1.5 levels, range 0-11 levels). There were no changes in the craniocaudal extension of the syrinx in 8 patients. By contrast, a considerable decrease in the anterior-posterior extension of the syrinx was noted in all patients. The mean anterior-posterior diameter ratio decreased from 0.67 (median 0.69 , range $0.17-1.00$ ) to 0.2 (median 0.17 , range $0.00-0.57$ ). The mean decrease was thus 0.47 (median 0.46, range 0.00-0.92), which was highly significant $(\mathrm{p}<0.00005)$.

In these 22 patients, the mean distance from the cerebellar tonsils to the C-2 level was $1.7 \mathrm{~cm}$ before surgery (median $2.0 \mathrm{~cm}$, range -0.4 to $3.2 \mathrm{~cm}$ ) and $2.4 \mathrm{~cm}$ after surgery (median $2.4 \mathrm{~cm}$, range $0.7-4.0 \mathrm{~cm}$ ). Mean postoperative tonsillar ascent was thus $0.7 \mathrm{~cm}$ (median $0.7 \mathrm{~cm}$, range -0.1 to $2.0 \mathrm{~cm}$ ). This difference, too, was highly significant $(\mathrm{p}<0.00005)$.

\section{Phase-Contrast Imaging}

Phase-contrast imaging demonstrated partial or complete obstruction of the pulsatile CSF flow at the craniocervical junction in all patients with CM-I. All but 4 patients also showed partial or complete blockage of CSF flow in the ventral subarachnoid space of the foramen magnum. Particularly noteworthy was a phase shift between the pulsations in the aqueduct and at the craniocervical junction (Fig. 1) and between the pulsations in the cervical subarachnoid space and the syrinx cavity (Fig. 2).

In 3 patients, phase-contrast MR imaging demonstrated CSF flow obstruction not only at the craniocervical junction but also in the spinal canal. Two of the 3 patients required surgery for persistent syringomyelia at these additional sites of obstruction. In both cases, the size of the syrinx was considerably reduced after surgery.

\section{Flow Velocities}

The highest flow velocities were measured in the ventral subarachnoid space of the cervical spine and in the prepontine subarachnoid space. When the sites of maximum pulsations were determined for each patient, maximum (caudal and cranial) pulsations at the craniocervical junction were detected most often in the prepontine sub-

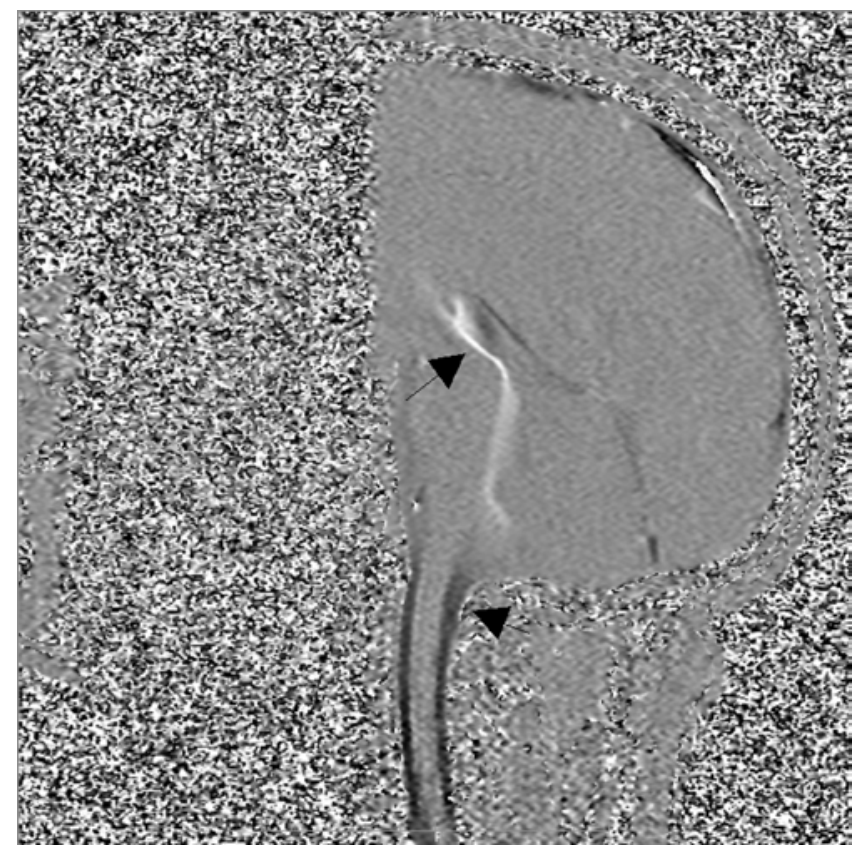

FIG. 1. Cardiac-gated phase-contrast MR image showing phase shift between pulsations in the aqueduct and the cerebellomedullary cistern in a patient with CM-I. The upper arrow points to the aqueduct, where CSF flows in the cranial direction (white). The lower arrow points to the subarachnoid space of the upper cervical canal, where CSF flows in the caudal direction (black). The image thus shows inhomogeneity and different directions of CSF flow in the region of obstruction at the level of the foramen magnum.

arachnoid space in patients both with and without syringomyelia (Table 1).

In the region of the cervical spine, more than half of the patients with syringomyelia showed maximum flow velocities (27 of 40 patients, 68\%) and minimum velocities (24 of 40 patients, 60\%) in the ventral subarachnoid space. In the region of the thoracic spine, the distribution of flow velocities was similar to that in the region of maximum extension of the syrinx because these 2 regions are often close to each other. In the region of maximum extension, each of the 3 measurement sites exhibited approximately one-third of the maximum pulsations. In the group of patients without syringomyelia, only 1 patient showed maximum pulsations and only 1 patient showed minimum pulsations in the region of the central canal.

An analysis of how flow velocities changed after surgical decompression revealed very interesting results. The difference between maximum and minimal velocities or, in other words, the velocity amplitude $(\Delta)$, considerably increased in the subarachnoid space with the exception of the region dorsal to the thoracic spinal cord (Table 2). In some cases, these changes were highly significant.

After decompression, an improvement in CSF flow was demonstrated in the region of the newly created cerebellomedullary cistern in all patients. Cerebrospinal fluid flow also improved in the ventral subarachnoid space.

The changes in pulsation were highly significant in the surgically enlarged cerebellomedullary cistern ( $\mathrm{p}=$ $0.0005)$. Also noteworthy was the change in the amplitude in the region where the syrinx was largest in diameter, 


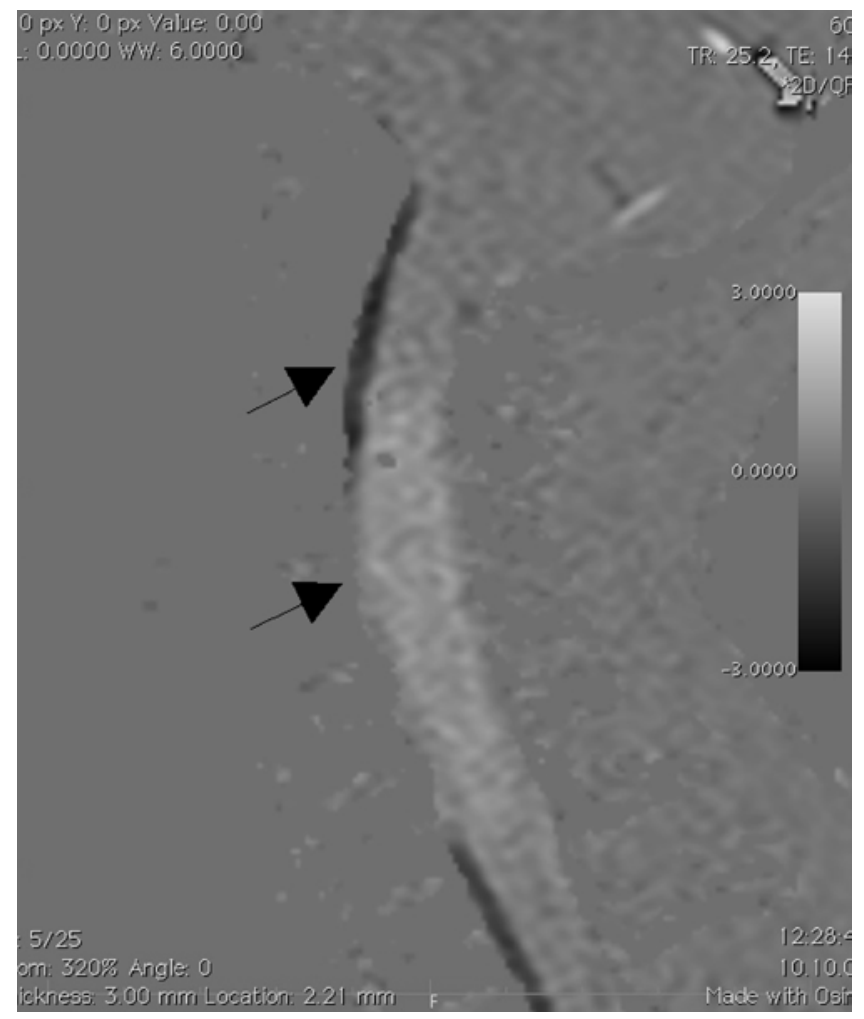

FIG. 2. Cardiac-gated phase-contrast MR image showing phase shift between pulsations in the subarachnoid space and the syrinx cavity in a patient with CM-I. The upper arrow points to ventral pulsations in the subarachnoid space of the upper cervical cord. The image shows complete compression of the subarachnoid space by the syrinx and ventral pulsations in the caudal direction. The lower arrow points to the area where the syrinx is largest in diameter. No pulsation can be detected in the subarachnoid space. Pulsations can only be observed in the syrinx cavity, where CSF flows in the cranial direction (white). The image thus reveals pulsations in opposite directions.

that is, in a region where the subarachnoid space was considerably wider after surgery. Maximum and minimum velocities increased considerably in this region. Tonsillar pulsations decreased, but not significantly. Interestingly, patients with a highly significant change in postoperative syrinx width $(\mathrm{p}<0.00005)$ showed changes in pulsations that were significant in the subarachnoid space in all spinal segments but were not significant in the syrinx itself and in the spinal canal.

Analogous comparisons between patients with and without syringomyelia revealed highly significant differences in flow velocity amplitudes only in the ventral cervical subarachnoid space $(\mathrm{p}<0.005)$ and less significant differences in the region of the thoracic central canal ( $p$ $<0.05)$.

\section{Discussion}

In large series of patients, the mean age of onset of CM-I is reported to be 25 years, and women account for $75 \%$ of patients..$^{22}$ In our study, a similarly high percentage of the patients were female (68\%). The mean age of onset, however, was considerably higher (almost 40 years). In our patient population, there was a clear relationship
TABLE 1: Mean minimum and maximum flow velocities in patients with $\mathrm{CM}-\mathrm{I}$

\begin{tabular}{|c|c|c|c|}
\hline \multirow[b]{2}{*}{ Location } & \multicolumn{3}{|c|}{ Velocity $(\mathrm{cm} / \mathrm{sec})^{*}$} \\
\hline & Minimum & Maximum & $\Delta$ \\
\hline \multicolumn{4}{|l|}{ aqueduct } \\
\hline CM-I w/ syringomyelia & -1.16 & 1.07 & 2.20 \\
\hline CM-I w/o syringomyelia & -0.74 & 1.13 & 1.88 \\
\hline CM-I after surgery & -1.65 & 1.95 & 3.40 \\
\hline \multicolumn{4}{|l|}{ 4th ventricle } \\
\hline CM-I w/ syringomyelia & -0.60 & 0.70 & 1.46 \\
\hline CM-I w/o syringomyelia & -0.66 & 0.69 & 1.35 \\
\hline CM-I after surgery & -1.29 & 1.11 & 2.36 \\
\hline \multicolumn{4}{|c|}{ prepontine subarachnoid space } \\
\hline CM-I w/ syringomyelia & -2.08 & 1.70 & 3.46 \\
\hline CM-I w/o syringomyelia & -2.33 & 1.87 & 4.20 \\
\hline CM-I after surgery & -2.77 & 2.47 & 4.94 \\
\hline \multicolumn{4}{|l|}{ pons } \\
\hline CM-I w/ syringomyelia & -0.40 & 0.53 & 1.16 \\
\hline CM-I w/o syringomyelia & -0.39 & 0.55 & 0.94 \\
\hline CM-I after surgery & -0.44 & 0.52 & 1.02 \\
\hline \multicolumn{4}{|l|}{ cerebellomedullary cistern } \\
\hline CM-I w/ syringomyelia & -0.78 & 0.88 & 1.66 \\
\hline CM-I w/o syringomyelia & -1.16 & 0.85 & 2.01 \\
\hline CM-I after surgery & -1.33 & 0.97 & 2.31 \\
\hline \multicolumn{4}{|l|}{ tonsil } \\
\hline CM-I w/ syringomyelia & -0.51 & 0.52 & 1.26 \\
\hline CM-I w/o syringomyelia & -0.54 & 0.56 & 1.10 \\
\hline CM-I after surgery & -0.53 & 0.65 & 1.19 \\
\hline \multicolumn{4}{|l|}{ ventral subarachnoid space† } \\
\hline CM-I w/ syringomyelia & -2.27 & 1.57 & 3.71 \\
\hline CM-I w/o syringomyelia & -3.33 & 2.03 & 5.36 \\
\hline CM-I after surgery & -3.65 & 2.79 & 6.37 \\
\hline \multicolumn{4}{|l|}{ central canal $\dagger$} \\
\hline CM-I w/ syringomyelia & -0.80 & 0.87 & 1.85 \\
\hline CM-I w/o syringomyelia & -0.52 & 0.72 & 1.21 \\
\hline CM-I after surgery & -0.88 & 1.06 & 1.94 \\
\hline \multicolumn{4}{|l|}{ dorsal subarachnoid space $†$} \\
\hline CM-I w/ syringomyelia & -1.68 & 1.24 & 2.81 \\
\hline CM-I w/o syringomyelia & -1.17 & 1.40 & 2.58 \\
\hline CM-I after surgery & -1.06 & 1.13 & 2.16 \\
\hline \multicolumn{4}{|l|}{ ventral subarachnoid space } \\
\hline CM-I w/ syringomyelia & -1.97 & 1.51 & 3.26 \\
\hline CM-I w/o syringomyelia & -1.65 & 1.56 & 3.22 \\
\hline CM-I after surgery & -3.30 & 2.29 & 5.40 \\
\hline \multicolumn{4}{|l|}{ central canal } \\
\hline CM-I w/ syringomyelia & -1.23 & 1.07 & 2.39 \\
\hline CM-I w/o syringomyelia & -0.53 & 0.62 & 1.16 \\
\hline CM-I after surgery & -0.77 & 0.93 & 1.71 \\
\hline
\end{tabular}

(continued) 
TABLE 1: Mean minimum and maximum flow velocities in patients with CM-I (continued)

\begin{tabular}{cccc}
\hline & \multicolumn{3}{c}{ Velocity $(\mathrm{cm} / \mathrm{sec})^{*}$} \\
\cline { 2 - 4 } Location & Minimum & Maximum & $\Delta$ \\
\hline dorsal subarachnoid space & & & \\
CM-I w/ syringomyelia & -1.81 & 1.47 & 3.17 \\
CM-I w/o syringomyelia & -2.32 & 1.76 & 4.09 \\
CM-l after surgery & -2.64 & 1.94 & 4.41 \\
ventral subarachnoid space§ & & & \\
CM-I w/ syringomyelia & -1.48 & 1.57 & 3.18 \\
CM-I after surgery & -3.78 & 2.63 & 6.19 \\
syrinx & & & \\
CM-I w/ syringomyelia & -1.48 & 1.23 & 2.77 \\
CM-I after surgery & -1.15 & 1.25 & 2.43 \\
dorsal subarachnoid space§ & & & \\
CM-I w/ syringomyelia & -1.55 & 1.47 & 3.05 \\
CM-l after surgery & -2.07 & 2.04 & 4.04 \\
\hline
\end{tabular}

* The velocity in the table was rounded to 2 decimal points, whereas the $\Delta$ value was calculated using the total amount of the velocity.

$\dagger$ Cervical spine.

$\ddagger$ Thoracic spine.

$\S$ Syrinx.

between patient age and the occurrence of syringomyelia. The development of syringomyelia in patients with CM-I appears to be only a matter of time.

Clinical manifestations of CM-I can be attributable to 3 causes: direct compression of the brainstem, an impair- ment of CSF drainage and hydrocephalus, and syringomyelia. Dissociated sensory loss, which is the classic clinical feature, was reported less frequently than expected. Milhorat et al. ${ }^{22}$ studied a large series of patients and found that dizziness, pressure in the ears, and tinnitus were the most common symptoms irrespective of the presence or absence of syringomyelia. The presence of headache, and especially headache linked to coughing, was found to be associated with a temporary increase in intracranial pressure. ${ }^{28}$ It was interesting to note the high incidence of headaches in patients without syringomyelia.

In the literature, the mean extent of tonsillar herniation is reported to be $11 \mathrm{~mm} .{ }^{19}$ This is similar to our findings (13 $\mathrm{mm})$. Mikulis et al. ${ }^{20}$ found a strong correlation between tonsillar descent and age and suggested that age must be considered in the definition of CM-I. Heiss et al. ${ }^{12}$ reported that patients who underwent surgery for CM-I showed a decrease in tonsillar herniation from a mean of $11 \mathrm{~mm}$ to a mean of $5.5 \mathrm{~mm}$ as early as 6 months after surgery. This finding is confirmed by our study, in which the mean postoperative tonsillar ascent was $7 \mathrm{~mm}$. These results suggest that cerebellar tonsil herniation is acquired and not congenital.

The literature provides only a paucity of studies attempting to explain why some patients with CM-I have syringomyelia and why others do not (or not yet). Stovner and Rinck $^{33}$ reported that syringomyelia was found significantly more frequently in patients with tonsillar herniation of 9-14 $\mathrm{mm}$ than in patients with a smaller or larger degree of herniation $(\mathrm{p}<0.001)$. These results, however, appear to be somewhat arbitrary and implausible and are not supported by our own experience.

TABLE 2: Comparison of preoperative and postoperative CSF flow velocities in 22 patients*

\begin{tabular}{|c|c|c|c|c|c|c|c|}
\hline \multirow[b]{2}{*}{ Location } & \multicolumn{6}{|c|}{ Velocity $(\mathrm{cm} / \mathrm{sec})$} & \multirow[b]{2}{*}{$\mathrm{p}$ Value } \\
\hline & Preop Min & Preop Max & Preop $\Delta$ & Postop Min & Postop Max & Postop $\Delta$ & \\
\hline aqueduct & -1.64 & 1.41 & 3.05 & -1.65 & 2.14 & 3.91 & 1.0 \\
\hline 4th ventricle & -0.81 & 0.69 & 1.50 & -1.26 & 0.92 & 2.18 & 0.27 \\
\hline prepontine subarachnoid space & -3.03 & 2.00 & 5.03 & -2.79 & 2.47 & 5.26 & 0.68 \\
\hline pons & -0.62 & 0.41 & 1.05 & -0.44 & 0.56 & 1.00 & 0.59 \\
\hline cerebellomedullary cistern & -0.57 & 0.56 & $1.12 \S$ & -1.42 & 0.99 & $2.40 \S$ & 0.0005 \\
\hline tonsil & -1.06 & 0.62 & 1.68 & -0.53 & 0.70 & 1.22 & 0.09 \\
\hline ventral subarachnoid space $\dagger$ & -2.52 & 1.50 & $4.03 \S$ & -3.69 & 2.72 & $6.41 \S$ & 0.005 \\
\hline central canal $\dagger$ & -1.24 & 0.93 & 2.16 & -0.88 & 1.15 & 2.04 & 0.93 \\
\hline dorsal subarachnoid space† & -1.94 & 1.07 & 3.00 & -1.04 & 1.24 & 2.28 & 0.07 \\
\hline ventral subarachnoid space $\ddagger$ & -1.79 & 1.44 & $3.24 \S$ & -1.79 & 2.29 & $5.67 \S$ & 0.003 \\
\hline central canalf & -0.83 & 1.21 & 2.04 & -0.65 & 0.87 & 1.54 & 0.58 \\
\hline dorsal subarachnoid spacef & -2.21 & 1.73 & 3.93 & -2.63 & 1.94 & 4.57 & 0.37 \\
\hline ventral subarachnoid space $\S$ & -1.24 & 1.30 & $2.60 \S$ & -3.93 & 2.69 & $6.76 \S$ & 0.00009 \\
\hline syrinx & -1.61 & 1.32 & $3.04 \S$ & -0.97 & 1.02 & $1.98 \S$ & 0.06 \\
\hline dorsal subarachnoid space§ & -1.04 & 1.10 & $2.05 \S$ & -2.12 & 2.05 & $4.17 \S$ & 0.001 \\
\hline
\end{tabular}

* Boldface $p$ values indicate a statistically significant difference. The velocity in the table was rounded to 2 decimal points, whereas the $\Delta$ value was calculated using the total amount of the velocity.

$\dagger$ Cervical spine.

$\ddagger$ Thoracic spine.

$\S$ Syrinx. 
It is still unclear whether systolic CSF flow is more impaired than diastolic CSF flow in patients with $\mathrm{CM}-\mathrm{I}^{4}$ or whether the opposite is true. ${ }^{14}$ Our results suggest that CSF flow is impaired in both directions. Whereas systolic CSF flow velocity is reduced or absent at the dorsal and ventral margins of the foramen magnum,,$^{25}$ velocity is elevated in the prepontine cistern. ${ }^{4}$ Milhorat et al ${ }^{22}$ reported that dorsal flow was impaired 3 times more often than ventral flow. However, it is difficult to compare available studies in this respect because there are no standardized measuring sites.

Our study did not confirm that surgical decompression can lead to a reversal of flow velocity abnormalities or a normalization of flow velocities. ${ }^{4}$ Some studies suggest that the duration of systolic caudal pulsations appears to be considerably longer in patients with CM-I than in patients without this condition and in patients who underwent surgical treatment. ${ }^{25}$ Phase-contrast MR imaging can visualize tonsillar pulsations but did not reveal differences between CM-I patients with or without syringomyelia. ${ }^{26}$

Successful surgical decompression should improve not only dorsal but also ventral CSF flow. ${ }^{24}$ Brugières et al. ${ }^{6}$ were able to show that effective decompression in patients with CM-I is associated with a postoperative decrease in CSF flow velocities in the syrinx. Whereas our results confirm this finding at a low level of significance, the velocity increase in the subarachnoid space was highly significant in the region where the syrinx was largest in diameter. One possible explanation is the marked postoperative increase in spinal cord volume in association with an increase in the contribution of the spinal cord to CSF pulsations. In addition, the CSF volume that had been shifted in the region of the syrinx was postoperatively shifted in the subarachnoid space. In contrast to our clear results, Iskandar and his working group ${ }^{7,11}$ reported a postoperative decrease in flow velocity. It should be noted, however, that their studies involved only 4 patients with syringomyelia and 4 patients without syringomyelia.

Normal preoperative CSF flow in the region of the craniocervical junction in spite of tonsillar descent of more than $5 \mathrm{~mm}$ appears to predict an unsatisfactory surgical outcome. ${ }^{19}$ This was to be expected considering the theories presented here. A seemingly trivial result, which, however, confirms the findings from phase-contrast MR imaging, is that syrinx size was significantly reduced in all patients with preoperative CSF flow obstruction at the craniocervical junction and postoperative reversal or improvement of CSF obstruction.

The indications for surgery in patients with CM-I remain controversial. A worldwide survey on the management of $\mathrm{CM}-\mathrm{I}^{30}$ showed consensus among pediatric neurosurgeons that no operation should be performed in asymptomatic patients with CM-I unless there is associated syringomyelia and that surgery should be performed in patients with CM-I when scoliosis and syringomyelia are present. There was no consensus about the management of patients without scoliosis. Haroun et al. ${ }^{10}$ who surveyed members of the Pediatric Section of the AANS, reported similar results. In this context, phase-contrast MR imaging can be useful. It demonstrates CSF flow obstruction at the craniocervical junction, especially in patients with borderline tonsillar herniation. This finding can contribute to a clinical decision for or against surgery. If surgery does not lead to a rapid decrease in syrinx size, phase-contrast MR imaging may nevertheless demonstrate an improvement in CSF flow and may thus show that a reduction in syrinx size can still be expected. Cerebrospinal fluid pulsation studies can provide evidence of additional causes of syringomyelia in the region of the vertebral column. Our research thus shows that a qualitative analysis of phase-contrast MR imaging can provide additional information and can thus help clinicians make a decision for or against surgery, and that a quantitative analysis is more of scientific than of clinical interest.

To our knowledge, there is no study reporting that a decrease in syrinx diameter is associated with a direct significant increase in flow velocity in the region where the syrinx was largest in diameter. This completely contradicts a current theory proposed by Greitz, ${ }^{9}$ who believes that syringomyelia develops passively as a result of the Venturi effect, which implies an increase in CSF velocity in narrow regions of the CSF pathways.

\section{Conclusions}

Cardiac-gated phase-contrast MR imaging can contribute to assessments of surgical outcomes in patients who underwent decompression for CM-I and can be a useful tool for identifying the cause of surgical failure. The results presented here raise doubts about current theories on the pathogenesis of syringomyelia.

\section{Disclosure}

The authors report no conflict of interest concerning the materials or methods used in this study or the findings specified in this paper.

Author contributions to the study and manuscript preparation include the following. Conception and design: Mauer. Acquisition of data: Mauer, Gottschalk, Mueller, Weselek. Analysis and interpretation of data: Mauer, Gottschalk, Mueller, Weselek. Drafting the article: Mauer, Mueller, Weselek. Critically revising the article: Gottschalk, Schulz. Reviewed submitted version of manuscript: Kunz. Approved the final version of the manuscript on behalf of all authors: Mauer. Statistical analysis: Mauer, Mueller, Weselek, Schulz. Administrative/technical/material support: Gottschalk, Kunz, Schulz. Study supervision: Kunz.

\section{References}

1. Badie B, Mendoza D, Batzdorf U: Posterior fossa volume and response to suboccipital decompression in patients with Chiari I malformation. Neurosurgery 37:214-218, 1995

2. Bergstrand G, Bergström M, Nordell B, Ståhlberg F, Ericsson A, Hemmingsson A, et al: Cardiac gated MR imaging of cerebrospinal fluid flow. J Comput Assist Tomogr 9:1003-1006, 1985

3. Bhadelia RA, Bogdan AR, Wolpert SM: Analysis of cerebrospinal fluid flow waveforms with gated phase-contrast MR velocity measurements. AJNR Am J Neuroradiol 16:389-400, 1995

4. Bhadelia RA, Bogdan AR, Wolpert SM, Lev S, Appignani BA, Heilman CB: Cerebrospinal fluid flow waveforms: analysis in patients with Chiari I malformation by means of gated phasecontrast MR imaging velocity measurements. Radiology 196:195-202, 1995 


\section{Cardiac-gated phase-contrast MR imaging and CM-I}

5. Brinkmann G, Harlandt O, Muhle C, Brossmann J, Heller M: Flussquantifizierung mit der Magnetresonanz-Tomographie: Eine experimentelle Studie an einem Flussmodell und Liquor-Flussmessungen im Aquaeductus cerebri bei Probanden. Fortschr Röntgenstr 172:1043-1051, 2000

6. Brugières $\mathrm{P}$, Idy-Peretti I, Iffenecker $\mathrm{C}$, Parker $\mathrm{F}$, Jolivet $\mathrm{O}$, Hurth M, et al: CSF flow measurement in syringomyelia. AJNR Am J Neuroradiol 21:1785-1792, 2000

7. Dolar MT, Haughton VM, Iskandar BJ, Quigley M: Effect of craniocervical decompression on peak CSF velocities in symptomatic patients with Chiari I malformation. AJNR Am J Neuroradiol 25:142-145, 2004

8. Edelman RR, Wedeen VJ, Davis KR, Widder D, Hahn P, Shoukimas G, et al: Multiphasic MR imaging: a new method for direct imaging of pulsatile CSF flow. Radiology 161:779-783, 1986

9. Greitz D: Unraveling the riddle of syringomyelia. Neurosurg Rev 29:251-264, 2006

10. Haroun RI, Guarnieri M, Meadow JJ, Kraut M, Carson BS: Current opinions for the treatment of syringomyelia and chiari malformations: survey of the Pediatric Section of the American Association of Neurological Surgeons. Pediatr Neurosurg 33:311-317, 2000

11. Haughton VM, Korosec FR, Medow JE, Dolar MT, Iskandar BJ: Peak systolic and diastolic CSF velocity in the foramen magnum in adult patients with Chiari I malformations and in normal control participants. AJNR Am J Neuroradiol 24: 169-176, 2003

12. Heiss JD, Patronas N, DeVroom HL, Shawker T, Ennis R, Kammerer W, et al: Elucidating the pathophysiology of syringomyelia. J Neurosurg 91:553-562, 1999

13. Hoffmann KT: Die intrakranielle Hirnwasserzirkulation in der Magnetresonanztomographie: Grundlagen der Bildgebung, Modellevaluation und klinische Anwendung von flußsensitiven Sequenzen zur Darstellung und Quantifizierung der intrakranialen Hirnwasserzirkulation [dissertation]. Universität Berlin, 2005

14. Hofmann E, Warmuth-Metz M, Bendszus M, Solymosi L: Phase-contrast MR imaging of the cervical CSF and spinal cord: volumetric motion analysis in patients with Chiari I malformation. AJNR Am J Neuroradiol 21:151-158, 2000

15. Kunz U: Klinische Anwendbarkeit flußsensitiver kernspintomographischer Verfahren bei Liquorzirkulationsstörungen [dissertation]. Universität Ulm: Habilitationsschrift, 1999

16. Levy LM: MR identification of Chiari pathophysiology by using spatial and temporal CSF flow indices and implications for syringomyelia. AJNR Am J Neuroradiol 24:165-166, 2003

17. Levy LM: MR imaging of cerebrospinal fluid flow and spinal cord motion in neurologic disorders of the spine. Magn Reson Imaging Clin N Am 7:573-587, 1999

18. Levy LM, Di Chiro G: MR phase imaging and cerebrospinal fluid flow in the head and spine. Neuroradiology 32:399406, 1990

19. McGirt MJ, Nimjee SM, Fuchs HE, George TM: Relationship of cine phase-contrast magnetic resonance imaging with outcome after decompression for Chiari I malformations. Neurosurgery 59:140-146, 2006

20. Mikulis DJ, Diaz O, Egglin TK, Sanchez R: Variance of the position of the cerebellar tonsils with age: preliminary report. Radiology 183:725-728, 1992

21. Milhorat T: Chiari and hindbrain-related syringomyelia. Br J Neurosurg 21:465-466, 2007 (Abstract)

22. Milhorat TH, Chou MW, Trinidad EM, Kula RW, Mandell M, Wolpert C, et al: Chiari I malformation redefined: clinical and radiographic findings for 364 symptomatic patients. Neurosurgery 44:1005-1017, 1999

23. Nitz WR, Bradley WG Jr, Watanabe AS, Lee RR, Burgoyne B, O'Sullivan RM, et al: Flow dynamics of cerebrospinal fluid: assessment with phase-contrast velocity MR imaging performed with retrospective cardiac gating. Radiology 183: 395-405, 1992

24. Panigrahi M, Reddy BP, Reddy AK, Reddy JJ: CSF flow study in Chiari I malformation. Childs Nerv Syst 20:336-340, 2004

25. Pinna G, Alessandrini F, Alfieri A, Rossi M, Bricolo A: Cerebrospinal fluid flow dynamics study in Chiari I malformation: implications for syrinx formation. Neurosurg Focus 8(3):E3, 2000

26. Pujol J, Roig C, Capdevila A, Pou A, Martí-Vilalta JL, Kulisevsky J, et al: Motion of the cerebellar tonsils in Chiari type I malformation studied by cine phase-contrast MRI. Neurology 45:1746-1753, 1995

27. Quencer RM, Post MJ, Hinks RS: Cine MR in the evaluation of normal and abnormal CSF flow: intracranial and intraspinal studies. Neuroradiology 32:371-391, 1990

28. Sansur CA, Heiss JD, DeVroom HL, Eskioglu E, Ennis R, Oldfield EH: Pathophysiology of headache associated with cough in patients with Chiari I malformation. J Neurosurg 98:453458,2003

29. Schellinger D, LeBihan D, Rajan SS, Cammarata CA, Patronas NJ, Deveikis JP, et al: MR of slow CSF flow in the spine. AJNR Am J Neuroradiol 13:1393-1403, 1992

30. Schijman E, Steinbok P: International survey on the management of Chiari I malformation and syringomyelia. Childs Nerv Syst 20:341-348, 2004

31. Schroth G: Physiologie und Pathologie der intrakraniellen Liquordynamik. Jahrbuch der Radiologie:287-290, 1991

32. Schroth G, Klose U: Cerebrospinal fluid flow. I. Physiology of cardiac-related pulsation. Neuroradiology 35:1-9, 1992

33. Stovner LJ, Rinck P: Syringomyelia in Chiari malformation: relation to extent of cerebellar tissue herniation. Neurosurgery 31:913-917, 1992

Manuscript submitted May 13, 2011.

Accepted July 14, 2011.

Address correspondence to: Uwe Max Mauer, M.D., Department of Neurosurgery, German Armed Forces Hospital, Oberer Eselsberg 40, D-89070 Ulm, Germany. email: uwe-max.mauer@dgn.de. 